\title{
Ethanolic extract of mangosteen (Garcinia mangostana) pericarp as sensitivity enhancer of doxorubicin on MCF-7 cells by inhibiting P- glycoprotein
}

\author{
NI PUTU LINDA LAKSMIANI \\ Department of Pharmacy, Faculty of Mathematics and Natural Sciences, Universitas Udayana. Bukit Jimbaran, Badung 80362, Bali, Indonesia \\ Tel.: +62-361-701954, email: lindalaksmiani@gmail.com
}

Manuscript received: 20 November 2018. Revision accepted: 23 February 2019.

\begin{abstract}
Laksmiani NPL. 2019. Ethanolic extract of mangosteen (Garcinia mangostana) pericarp as sensitivity enhancer of doxorubicin on MCF-7 cells by inhibiting P-glycoprotein. Nusantara Bioscience 11: 49-55. Generally, doxorubicin is used in combination with other anticancer agents. Reduction side effects tend to be better in combination use than the use of single doxorubicin. Therefore the development of anticancer agents with low side effects and combination agents that decrease the side effects of doxorubicin still need to be pursued. The use of doxorubicin also shows a phenomenon of resistance due to over-expression of P-glycoprotein (Pgp). The research was conducted to evaluate the cytotoxic effect of lower dose doxorubicin combine with ethanolic extract of mangosteen pericarp (EEMP) on MCF-7 cells and determine the mechanism of alpha ( $\alpha$ )-mangostin as the active compound in EEMP that contribute increasing sensitivity of doxorubicin on MCF-7 through Pgp by in silico. The cytotoxic activity was observed using 3-(4,5dimethylthiazol-2-yl)-2,5-diphenyl tetrazolium bromide (MTT) assay. Molecular docking with 4.2 autodock program was used to evaluate the interaction of $\alpha$-mangostin with Pgp. EEMP has IC50 of $54 \mu \mathrm{g} / \mathrm{mL}$ on MCF-7 cells while for doxorubicin has IC 50 of 1392 nM. Exposure EEMP enhanced cytotoxic effect of doxorubicin on MCF-7 cells. Solely doxorubicin $750 \mathrm{nM}$ treatment gave cell viability percentage $94.98 \%$, but when combined with EEMP $22.5 \mu \mathrm{g} / \mathrm{mL}$, the cell viability percentage was reduced to $16.91 \%$. This shows that EEMP potent to be used as a combination agent for doxorubicin chemotherapy. The in silico assay demonstrate that $\alpha$-mangostin has an affinity for Pgp with binding energy of $-6.13 \mathrm{kcal} / \mathrm{mol}$.
\end{abstract}

Keywords: Combination, EEMP, MCF-7, doxorubicin, Pgp

\section{INTRODUCTION}

Cancer cells maintain themselves to stay alive from various radiation treatments and chemotherapy agents. Cancer cells try to avoid cell cycle arrest or apoptosis (Hassan et al. 2014; Liu et al. 2015). They unresponse to antiproliferative signals and have their own growth factors to proliferate continuously. In addition, cancer cells avoid the apoptosis mechanism when abnormalities occur (Hanahan et al. 2011). These two things become important targets of chemotherapy agents. Even cancer cells that are sensitive to chemotherapy agents with its mechanism induce cell cycle arrest and apoptosis, cancer cells at some point turn out to be resistant to these agents (Shah et al. 2001; Ricci et al. 2006; Pistritto et al. 2016). There is molecular evidence that cancer cell resistance due to chemotherapy by the increased expression of $\mathrm{Bcl}-2$ and Pglycoprotein (Pgp) (Bao et al. 2012; Housman et al. 2014; Geretto et al. 2017). Bcl-2 gene has a function to increase cell immunity against the detachment of apoptosis and Pgp as a protein transporter to maintain low concentrations of chemotherapeutic agents in cells by pumping drugs out of the cell (Alfarouk et al. 2015; Li et al. 2016). One alternative to overcome cancer cell resistance is combination therapy with several drugs. However, cancer cell resistance can also occur due to improper chemotherapy agent combination regimens. Resistance to major chemotherapeutic agents can be mediated by differences in the target inhibition in the cell cycle phase. Combination agents can actually weaken the main chemotherapeutic agent by blocking its action in the cell cycle so that the apoptosis mechanism is inhibited. In this case, the optimization of drug combination is needed including the method of giving each sole agent to the patient.

Doxorubicin is an anthracycline class antibiotic that is widely used for the treatment of various types of cancers such as acute leukemia, breast cancer, bone and ovarian cancer (Kumar et al. 2014). Generally, doxorubicin is used in combination with other anticancer agents such as cyclophosphamide, cisplatin, and 5-FU. The combination of doxorubicin and anticancer agents or co-chemotherapy agents from natural ingredients is expected to reduce the side effects and phenomena of cancer cell resistance. The doxorubicin resistance is caused by the over-expression of Pgp so that doxorubicin to be pumped out of the cell leading to the dropped concentration of doxorubicin in the cell. Therefore another or combination agents are needed to overcome the problem of doxorubicin resistance and to reduce the side effects of using doxorubicin.

One plant that has the potential to be developed as a companion agent for doxorubicin is mangosteen pericarp. The mangosteen pericarp turns out to have a cytotoxic effect and cell cycle modulation. Mangosteen pericarp has 
cytotoxic effects on MCF-7 cells (Setiawati et al. 2014), SKBR3 cells (Moongkarndi et al. 2004) and T47D cells (Rofida et al. 2017) with $\mathrm{IC}_{50}$ each of them were $45 \mu \mathrm{g} / \mathrm{mL}$, $15.45 \mu \mathrm{g} / \mathrm{mL}$ and $8.96 \mu \mathrm{g} / \mathrm{mL}$, respectively. $\alpha$-mangostin is an active ingredient isolated from mangosteen pericarp which is cytotoxic to cancer cells. Akao et al. 2008 reported that $\alpha$-mangostin is cytotoxic in DLD-1 cells of human colon cancer with $\mathrm{IC}_{50} 7.5 \mu \mathrm{M}$. Based on this, mangosteen pericarp is a potential source of anticancer or combination agent to reduce the cancer drug resistance with specific molecular targets. Various types of compounds have been shown to be able to inhibit the work of Pgp, including alkaloid compounds, flavonoids, and xanthones. The approach of the chemical structure of the $\alpha$ mangostin compound from xanthone is the basic compound which can be potentially used as Pgp inhibitor. This study was designed to evaluate the cytotoxic effect of combination of EEMP and doxorubicin in MCF-7 cells and to investigate the molecular mechanism of $\alpha$-mangostin in EEMP through inhibiting Pgp as target protein by in silico to increase the sensitivity cytotoxic effect of lower-dose usage of doxorubicin.

\section{MATERIALS AND METHODS}

\section{Sample collection}

The pericarp of mangosteen (Garcinia mangostana L.) was collected from traditional market in Pupuan, Tabanan, Bali, Indonesia.

\section{Chemical materials}

Ethanol $70 \%$ was purchased from Trio Brothers, Surabaya, Indonesia, advanced Dulbecco`s modified Eagle's medium (DMEM) and Fetal Bovine Serum (FBS) (Sigma-Aldrich USA), Doxorubicin, Penicillin, streptomycin, fungizone, and MTT were obtained from Sigma Aldrich, Germany, Trypsin-EDTA was supplied from Gibco, Dimethylsulfoxide (DMSO) (Sigma), Sodium Dodecyl Sulfate Solution (SDS) (Merck) and Phosphate Buffer Saline (PBS) (Sigma).

\section{Extraction of mangosteen pericarp}

Dried mangosteen pericarp was ground into powder and extracted by maceration with ethanol $70 \%$. The ratio of powder sample and solvent was 1:10 (for $48 \mathrm{~h}$ ). The ethanolic extract was pressured using rotary evaporator.

Cytotoxicity and Cell viability assay: 3-(4,5-

\section{dimethylthiazol-2-yl)-2,5-diphenyltetrazolium bromide (MTT) assay}

Cells with concentration of $5 \times 10^{3}$ cells/well distributed into the 96-well plate were incubated for $24 \mathrm{~h}$ prior to addition of test compound. Afterward, the medium was removed and the cells were washed with PBS. Various series of test compounds (EEMP and doxorubicin) in the culture medium were added both solely and in combination. They were then incubated for 24 hours at $5 \%$ $\mathrm{CO}_{2}$ incubator at temperature of $37^{\circ} \mathrm{C}$. After 24 hours of incubation, the medium was removed and the cells were washed with $100 \mu \mathrm{L}$ of PBS followed by adding to each mixture $100 \mu \mathrm{l}$ MTT reagent $0.5 \mathrm{mg} / \mathrm{ml}$ in DMEM HighGlucose medium and incubated for 3-4 hours in $5 \% \mathrm{CO}_{2}$ incubator with the temperature of $37^{\circ} \mathrm{C}$. Living cells will react with MTT to form purple color. The MTT reaction was stopped with a reagent stopper (SDS $10 \%$ in $0.1 \mathrm{~N}$ $\mathrm{HCl}$ ), which was then incubated overnight at room temperature and in a dark place (covered with aluminum foil). The next day, the plate was shaken for 10 minutes, and the absorption was read by an ELISA reader at a wavelength of $595 \mathrm{~nm}$.

\section{Molecular docking \\ Target protein preparation}

Protein preparation began by selecting the structure of the protein in an active form which bound to native ligand namely Pgp (GDP ID: 5KOY). The native ligand on the target protein was then eliminated by the Chimera 1.10 .1 program aiming to provide pocket/cavity so that the pocket coordinates and binding site center as docking material could be known. The ligands of each target protein were also separated for method validation.

\section{Alpha-mangostin optimization}

The 3-dimensional structure of $\alpha$-mangostin compound was optimized using the Hyperchem 8 program complete with hydrogen atoms. The optimization of the 3dimensional structure of $\alpha$-mangostin was done using AM1 semi-empirical computational methods and single-point calculations and geometry optimization. Single point calculations were used to find out the total energy of the $\alpha$ mangostin configurations, while geometry optimization was used to find stable configuration values with lower values than single point calculations.

\section{Molecular docking method validation}

Validation of the molecular docking method was done by redocking the native ligand of each target protein to the target protein previously removed by the native ligand. Redocking was done using the Autodock 4.2 program. The results of the docking validation analysis showed the compound with conformation, which has the lowest bond energy to bind to the target protein. Root mean square distances (RMSD) compound docking results were then compared with references. The method was valid if the value of RMSD was $\leq 3 \AA$. Afterward, docking of the test compound on the target protein could be done (Jain and Nicholls 2008).

\section{Docking $\alpha$-mangostin to Pgp as target protein}

The optimization result of $\alpha$-mangostin was then docking to the target protein, which has been prepared (the native ligand was omitted). Docking was done using the Autodock 4.2 program. The results of the analysis will show the compound with confirmation with the lowest bond energy to bind to the target protein. 


\section{Data analysis}

Single compound cytotoxic test using MTT assay

In the cytotoxicity assay using MTT method, the calculation of $\%$ cell death due to treatment was conducted by comparing the difference in the absorbance of the solution from the cell control with the absorbance of the solution from the treated cell to the absorbance of the solution from the cell control multiplied by $100 \%$ (Equation (1). To determine whether or not there is a cytotoxic effect, a computerized linear regression analysis is performed to obtain the $\mathrm{IC}_{50}$ value.

$\%$ Viable cells $=\frac{\text { Treated cells abs }- \text { medium control abs }}{\text { Cells control abs }- \text { medium control abs }} \times 100 \%$

Combination cytotoxic test using MTT assay (co-

chemotherapy application analysis)

The combined effect of $\alpha$-mangostin-doxorubicin could be analyzed by evaluating the percentage of cell viability from the treatment of each concentration used both singular and a combination. Data was then analyzed by ANOVA with a confidence level of $95 \%$.

\section{Molecular docking analysis}

Molecular docking results are binding energy. Binding energy values indicated the bond strength between compounds and proteins. The lower binding energy value means that the bond was stronger and more stable. If the binding energy between $\alpha$-mangostin and Pgp as target protein was getting lower, then the interaction between $\alpha$-mangostin and Pgp was stronger so that $\alpha$-mangostin in EEMP has the potential as a Pgp inhibitor. Pgp, a reflux pump protein that comes out drugs from the cell cause the drug concentration in the cell decreases and will need a larger dose to get the same effect. Pgp is one of protein that responds to resistance event. Molecular docking result show EEMP inhibit Pgp that occur to EEMP enhance the sensitivity of chemotherapy agents and less resistance of drugs.

\section{RESULTS AND DISCUSSION}

\section{Ethanolic extract of mangosteen pericarp performed cytotoxic to MCF-7 cells}

Cytotoxic assay was carried out to determine the cell toxicity potential of the compound expressed in $\mathrm{IC}_{50}$ parameters. The test was carried out with MTT assay, where the absorbance of purple formazan salt was formed due to the reduction of reagent MTT tetrazolium salt which was yellow because of the succinate dehydrogenase enzyme found in living cells (Bahuguna et al. 2017). The intensity of purple crystal is measured at a wavelength of $595 \mathrm{~nm}$. Color intensity is proportional to the number of living cells, the obtained absorbance could be converted to the percentage of cell viability.

EEMP treatment with series content of $12.5 ; 25 ; 50$; $62.5 ; 75$ and $87.5 \mu \mathrm{g} / \mathrm{mL}$ for 24 hours applied in this study. Results showed that higher treatment doses gave a decrease in cell viability, indicating a correlation between the concentration of the test solution and the cytotoxic effects occurred. It also showed that a dose-dependent phenomenon, cytotoxic effects increase with the increase of concentration. The increase in cytotoxic effects was indicated by the smaller percentage of living cells after it was treated in higher concentrations of test compound or extract. The greater concentration of extract, the absorbance value is smaller, which means smaller number of living cells. IC ${ }_{50}$ of EEMP to MCF-7 cell was $54 \mu \mathrm{g} / \mathrm{mL}$ (Figure 1). The cell morphology of MCF-7 which died because of the extract treatment could be observed in figure 2. Cell morphology changes significantly since the EEMP concentration increased. EEMP caused changes in cell morphology to become rounded, irregular and experience condensation before it died.

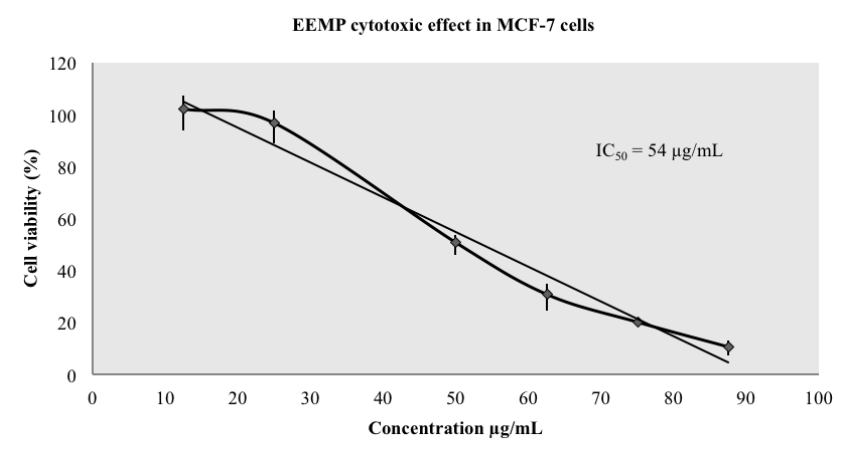

Figure 1. Effect of ethanolic extract of mangosteen pericarp (EEMP) on MCF-7 cell viability by using MTT assay

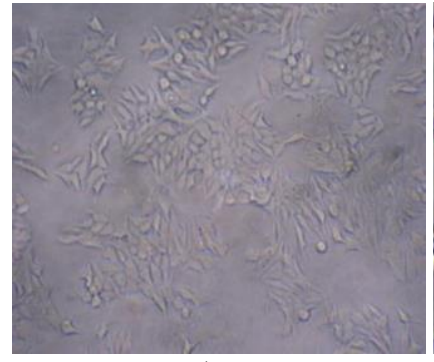

A

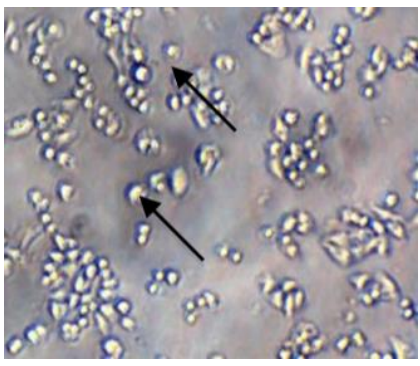

B

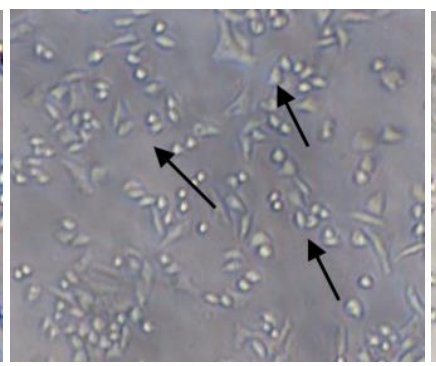

C

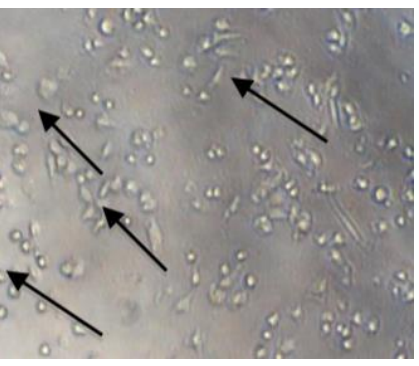

D

Figure 2. Morphology changing of MCF-7 cells after treated by ethanolic extract of mangosteen pericarp (EEMP). Cell control (a), after 24 hours $12.5 \mu \mathrm{g} / \mathrm{mL}$ EEMP treatment (b), $25 \mu \mathrm{g} / \mathrm{mL}$ EEMP treatment (c), $50 \mu \mathrm{g} / \mathrm{mL}$ EEMP treatment (d). The cell morphology changes showed by arrow $(\longrightarrow$ ) 


\section{Ethanolic extract of mangosteen pericarp enhanced cytotoxic activity of doxorubicin on MCF-7 cells}

Combination tests were carried out to analyze the effects of EEMP and doxorubicin on MCF7-7 cells. The efficacy of those combinations is synergistic, additive, or antagonistic. Synergistic combinations of them can increase the efficacy of doxorubicin resulting in a decrease in the treatment dose to obtain the same level of cytotoxic effect. The interaction of EEMP and doxorubicin on MCF7 cells was observed by the combination of cytotoxic test using lower concentrations than the $\mathrm{IC}_{50}$ single treatment of each test compound, which was then analyzed their percentage of cell viability.

The combination of EEMP and doxorubicin with concentration of $22.5 \mu \mathrm{g} / \mathrm{mL}$ EEMP and $750 \mu \mathrm{nM}$ doxorubicin produced percentage of MCF-7 cell viability is
$16.91 \%$ (Figure 3 ). The percentage of cell viability is still high at $94.89 \%$ due to treatment with single doxorubicin was $750 \mathrm{nM}$. It means that the EEMP increased the cytotoxic effect of doxorubicin. This also shows that EEMP has the potential to be used as a companion (cochemotherapy) agent for doxorubicin chemotherapy. The lower doses of doxorubicin could reduce its side effects, interestingly the activity of this agent could still be maintained, which could be seen from the decreased percentage of viability of MCF-7 cells caused by the EEMP exposure. Figure 4 demonstrates the changing in cell morphology occurring because of combination treatments. The cell nucleus appeared to shrink, and some cells underwent membrane blebbing, while the boundary between cells was very thin, and the cell indicated in apoptosis process

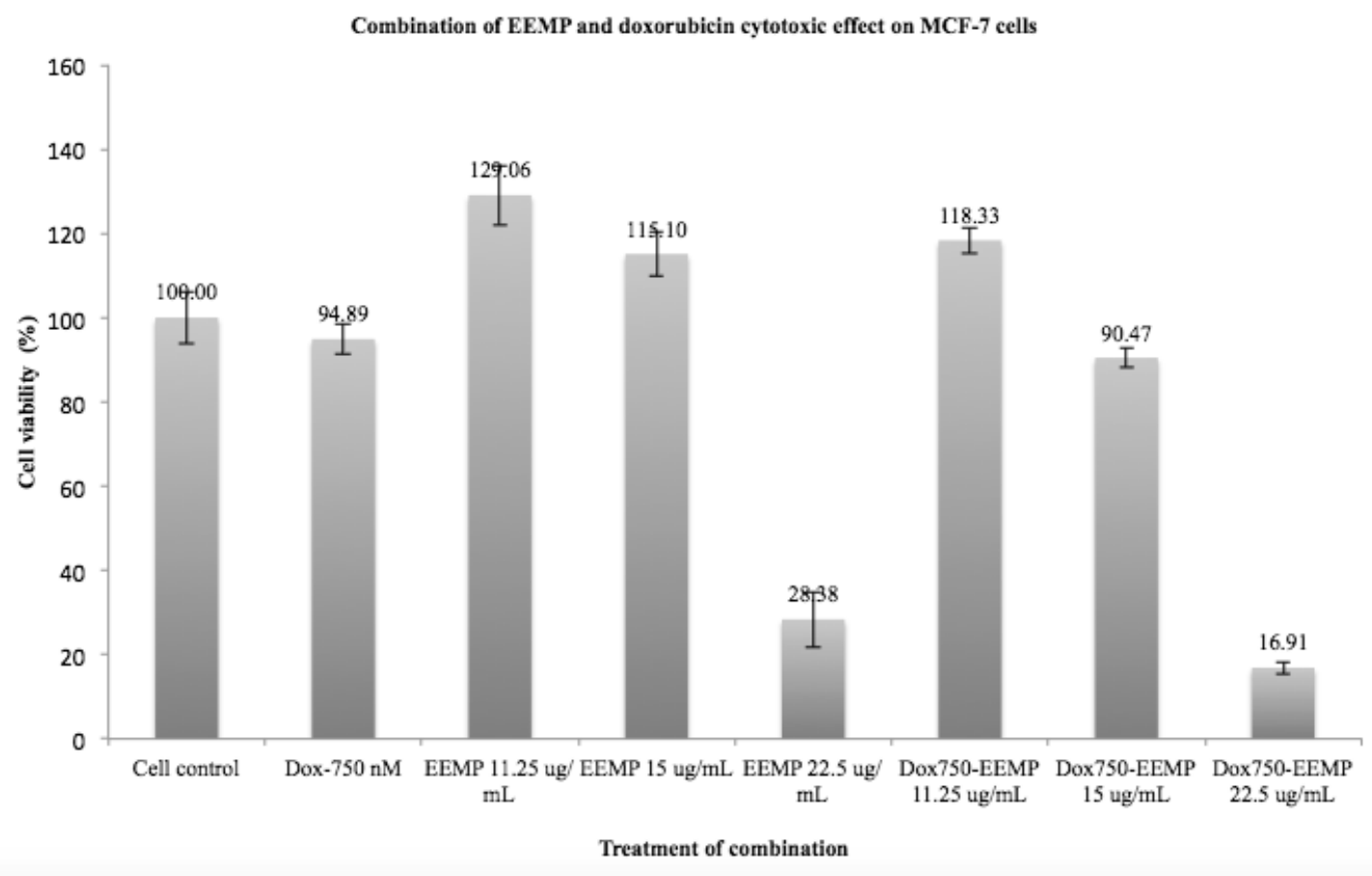

Figure 3. The cytotoxic effect of combination treatment of ethanolic extract of mangosteen pericarp (EEMP) and doxorubicin (Dox). Results are shown as mean \pm SD $(n=3)$

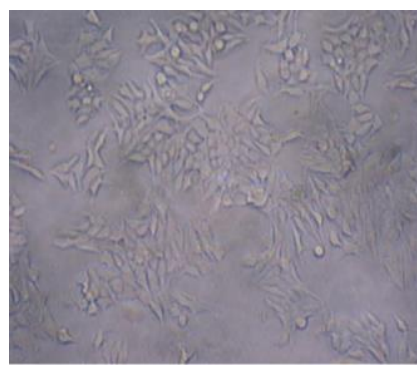

$\mathbf{A}$

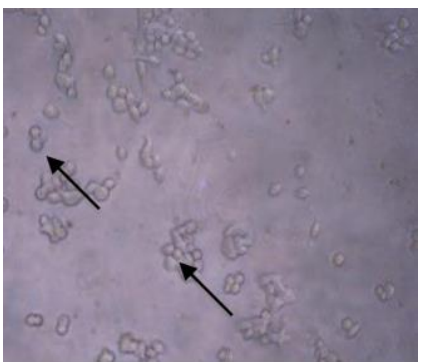

B

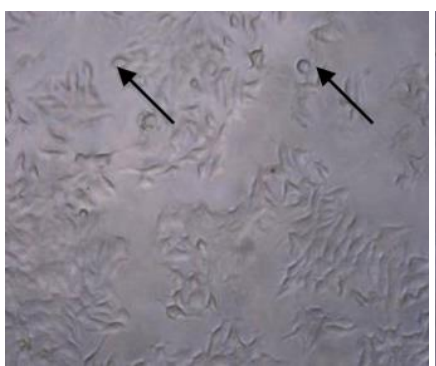

C

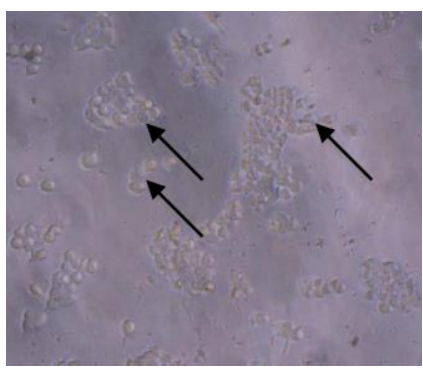

D

Figure 4. Effect of combination of ethanolic extract of mangosteen pericarp (EEMP) and doxorubicin on MCF-7 cells undergo morphological changes. Cell control (A); $22.5 \mu \mathrm{g} / \mathrm{mL}$ EEMP exposure (B); Doxorubicin $750 \mathrm{nM}$ exposure (C); combination $22.5 \mu \mathrm{g} / \mathrm{mL}$ EEMP and $750 \mathrm{nM}$ doxorubicin exposure (D) 
Ethanolic extract of mangosteen pericarp (EEMP) with $\alpha$-mangostin as active compound potentially increases the cytotoxic effect of doxorubicin by inhibiting the target protein Pgp

Molecular docking is designed to determine the molecular mechanisms mediating EEMP cytotoxic effects in silico. Molecular docking test results using the Autodock 4.2 program were listed in Table 1, while the interactions between $\alpha$-mangostin and Pgp could be seen in Table II. In the validation process, 10 native ligand bond conformations to the target protein were obtained. From the 10 conformations, one conformation was chosen with the lowest RMSD (Root Mean Square Deviation) value. RMSD is a measurement representing the deviation of the obtained native ligand bond position experimentally compared to the actual one. If RMSD value was greater, the deviation of the bond position was also greater. Therefore, the possibility of bond prediction errors of the test compound was also getting bigger when docking was complete (Bordogna et al. 2011; Kufareva and Abagyan 2012). The RMSD value obtained in this study was $2.74 \AA$
(Table I). A molecular docking method is valid if it has a value of $\mathrm{RMSD} \leq 3 \AA$.

\section{Discussion}

This study aims to explore the natural ingredients of mangosteen pericarp which has the potential as a cochemotherapeutic agent in the treatment of breast cancer. Doxorubicin as one of the widely used chemotherapeutic agents also affects normal tissues, immune system suppression, and resistance. Chemotherapy is a cancer therapy strategy by combining a compound with chemotherapy agents. Combinations with phytochemical compounds can be used as a choice. Therefore, the effect of mangosteen pericarp usage both as substituents and complement, in the treatment of breast cancer was studied. The first study was carried out to the single EEMP cytotoxic potency. The results of this study with the MTT assay method showed that EEMP was able to inhibit the growth of MCF-7 cells with an $\mathrm{IC}_{50}$ value of $54 \mu \mathrm{g} / \mathrm{mL}$. This value shows a potent cytotoxic effect, which was under $100 \mu \mathrm{g} / \mathrm{mL}$ (Ueda et al. 2002).

Table 1. RMSD value of molecular docking validation method and binding energy of $\alpha$-mangostin with Pgp using molecular docking

\begin{tabular}{|c|c|c|c|c|c|c|}
\hline No. & Target proteins & $\operatorname{RMSD}(\AA)$ & Ligand & $\begin{array}{c}\text { Binding energy } \\
(\mathrm{kcal} / \mathrm{mol})\end{array}$ & Hydrogen bond & $\begin{array}{l}\text { (Ligand-protein) } \\
\text { group }\end{array}$ \\
\hline \multirow[t]{8}{*}{1} & \multirow[t]{8}{*}{ Pgp (5KOY) } & \multirow[t]{8}{*}{2.74} & Native ligand & \multirow[t]{5}{*}{-7.01} & GLY 428 & $\mathrm{O} 3-\mathrm{HN}$ \\
\hline & & & & & SER 430 & O1G-HN \\
\hline & & & & & ASP 160 & HN61-OD2 \\
\hline & & & & & LYS 429 & O2G-HZ2 \\
\hline & & & & & LYS 429 & O2G-HN \\
\hline & & & $\alpha$-mangostin & \multirow[t]{3}{*}{-6.13} & ASP 160 & $\mathrm{H}-\mathrm{OD} 2$ \\
\hline & & & & & THR 431 & $\mathrm{O}-\mathrm{HN}$ \\
\hline & & & & & ARG 901 & $\mathrm{O}-\mathrm{HH} 21$ \\
\hline
\end{tabular}

Table 2. Interaction between of $\alpha$-mangostin with target protein Pgp with amino acid residue on target protein

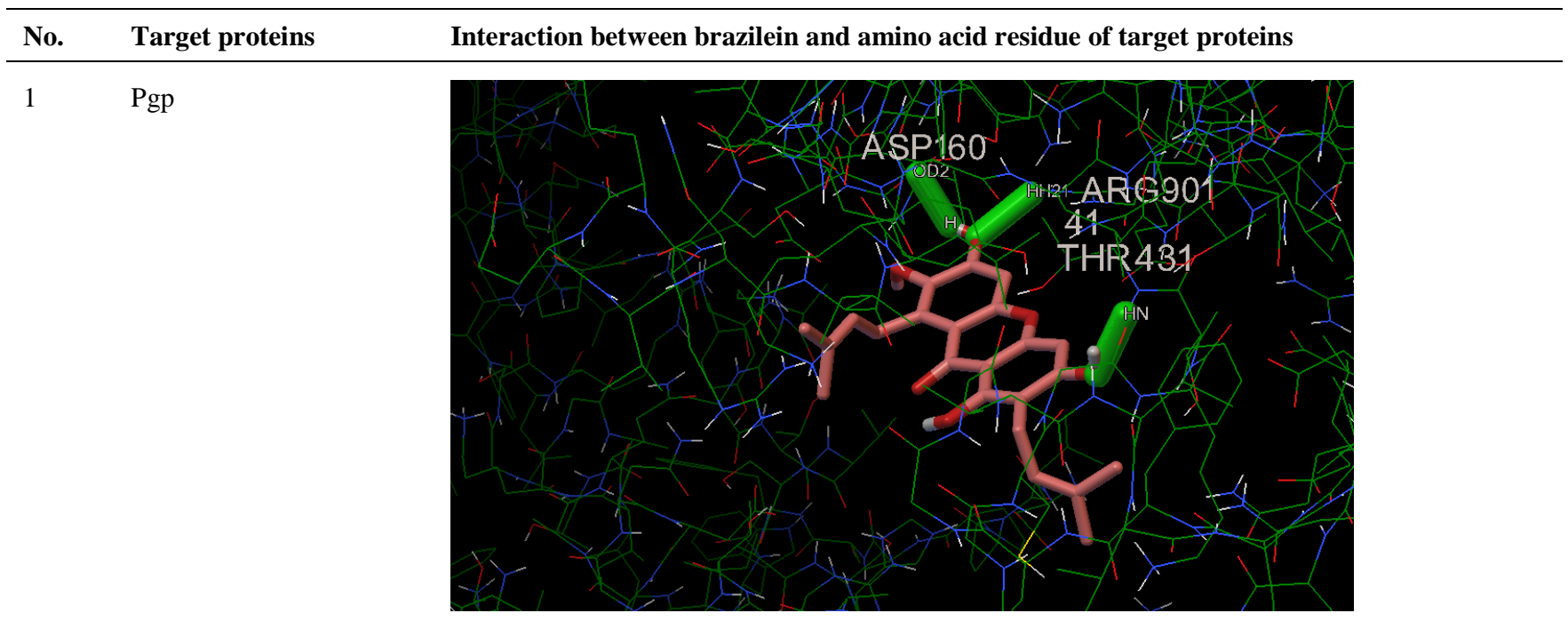


When the dose of extract treatment increases, which is in line with the decrease in cell viability, it means that the inhibitory effect is dose-dependent. The growth inhibition by this extract could also be caused by the content of active substance namely $\alpha$-mangostin. $\alpha$-mangostin which is the major component of EEMP is capable to induce the cell death in oral squamous cell carcinoma cell (Kwak et al. 2016) and to induce the apoptosis in human osteosarcoma cell line MG63 (Park et al. 2018). $\alpha$-mangostin has been shown to inhibit the proliferation pathway through p38 mitogen-activated protein kinase (MAPK) and to induce the apoptosis mechanism by increasing the levels of Bax, followed by the activation of the caspase 3 and caspase 9 (Lee et al. 2016). Those protein are involved in the regulation of cell death, cell cycle development, and cell division so that the mechanism mediating EEMP inhibition is the induction of apoptosis or the inhibition of the cell cycle in certain phases. The potent cytotoxic activity shows that EEMP could be developed specifically as a combination with doxorubicin breast cancer chemotherapy agents to improve its efficacy. Doxorubicin has a cytotoxic effect on MCF-7 with $\mathrm{IC}_{50} 1392 \mathrm{nM}$. However, subsequent exposure to doxorubicin will trigger resistance. Resistance mechanism of doxorubicin in MCF-7 cells is the overexpression of antiapoptotic proteins $\mathrm{Bcl}-2$ and Pgp. Therefore, to increase the cytotoxic effect of doxorubicin on MCF-7 cells, it was combined with EEMP.

EEMP and doxorubicin interactions in $\mathrm{MCF}-7$ cells were observed by combination cytotoxic tests using low concentrations of the $\mathrm{IC}_{50}$ single treatment of each test compound followed by the percentage of cell viability analysis. The combination treatment of EEMP and doxorubicin with each used concentration showed that a higher inhibitory has an effect on the growth of MCF-7 cells compared to a single treatment of each compound and was able to inhibit cell growth up to $50 \%$ of the population. From the results of the combination of cytotoxicity test between EEMP and doxorubicin, it showed that EEMP can be developed into a co-chemotherapy agent so that the concentration of doxorubicin producing the cell inhibition up to $50 \%$ of the population could be reduced. Decreasing the concentration of doxorubicin correlates directly with the decrease of side effects and toxicity as well as cases of resistance caused by doxorubicin. Figure 3 demonstrates that EEMP enhanced the cytotoxicity effect of doxorubicin. Single doxorubicin application with concentration of 750 $\mathrm{nM}$ exposed to MCF-7 cells still resulted in the percentage of cell viability about $94.89 \%$, but when it was combined with EEMP $22.5 \mu \mathrm{g} / \mathrm{mL}$, the percentage of cell viability become $16.91 \%$.

The strong activity of EEMP can occur through a variety of mechanisms, including induction of apoptosis and cell cycle modulation. In the EEMP and doxorubicin combination test, there was a change in cell morphology when it was compared with the single treatment of each test compound (Figure 4). Almost all cells experienced cell shrinkage and morphological changes in these cells led to indications of apoptosis. Further research is needed to determine the mechanism for increasing cytotoxic activity from a combination of EEMP and doxorubicin against
MCF-7 cells. Therefore, in silico assay was conducted to trace and provide an overview of the molecular mechanism of $\alpha$-mangostin with Pgp used as target protein, which caused EEMP to increase the sensitivity of cytotoxic effect of doxorubicin (Toffoli et al. 1996). Tracking the molecular mechanism of $\alpha$-mangostin was carried out using molecular docking by in silico on Pgp protein.

Molecular docking analysis of $\alpha$-mangostin was evaluated from the binding site of Pgp after the preparation of the target protein, to determine the affinity of $\alpha$ mangostin in Pgp and the inhibition of the target protein. These obstacles will disrupt Pgp activities because there was no energy used in the active transport process by Pgp (Aller et al. 2009). From the results of molecular docking in tables I and II, interactions $\alpha$-mangostin was weaker than native ligand because it had higher binding energy value, $6.13 \mathrm{kcal} / \mathrm{mol}$ compared to native ligand $-7.01 \mathrm{kcal} / \mathrm{mol}$ (Table I). Nevertheless, the interaction of $\alpha$-mangostin at Pgp binding site is quite strong, as evidenced by the presence of 3 hydrogen bonds between $\alpha$-mangostin and amino acid residues in Pgp, which is similar to amino acid residues (ASP 160). This could be seen from the interaction between $\alpha$-mangostin at Pgp binding site when it was compared with the interaction between native ligands in the same pocket from Pgp. However, further research to find out $\alpha$-mangostin in EEMP inhibiting Pgp activity in vitro should be done.

It can be concluded that EEMP cytotoxic on MCF-7 cells and its combination with doxorubicin increases the cytotoxic activity of doxorubicin chemotherapy agent, which may be related to MCF-7 cell apoptosis induction and the inhibition of Pgp expression. The results of this study are expected to give scientific data regarding the use of EEMP, specifically as a co-chemotherapy agent for breast cancer with doxorubicin.

\section{ACKNOWLEDGEMENTS}

The author would like to thank Udayana University for funding this research (PUPS 2018) and Cancer Chemoprevention Research Center (CCRC) for supporting both material and non-material of the implementation of this research.

\section{REFERENCES}

Akao Y, Nakagawa Y, Iinuma M, Nozawa Y. 2008. Anti-cancer effects of xanthones from pericarps of mangosteen. Intl J Mol Sci 9: 355-370.

Alfarouk KO, Stock CM, Taylor S, Walsh M, Muddathir AK, Verduzco D, Bashir AHH, Mohammed OY, Elhassan GO, Harguindey S, Reshkin SJ, Ibrahim ME, Rauch C. 2015. Resistance to cancer chemotherapy: failure in drug response from ADME to P-gp. Cancer Cell Intl 15: 71.

Aller SG, Yu J, Ward A, Weng Y, Chittanoina S, Zhou R, Harrel PM, Trinh YT, Zhang Q, Urbatsch IL, Chang G. 2009. Structure of Pglycoprotein reveals a molecular basis for poly-specific drug binding. Science 323: 171-172.

Bahuguna A, Khan I, Bajpai VK, Kang SC. 2017. MTT assay to evaluate the cytotoxic potential of a drug. Bangladesh J Pharmacol 12: 115118 . 
Bao L, Hazari S, Mehra S, Kaushal D, Moroz K, Dash S. 2012. Increased expression of P-glycoprotein and doxorubicin chemoresistance of metastatic breast cancer is regulated by miR-298. Am J Pathol 180: 2490-2503.

Bordogna A, Pandini A, Bonati L. 2011. Predicting the accuracy of protein-ligand docking on homology models. J Comput Chem 32: 8198.

Geretto M, Pulliero A, Rosano C, Zhabayeva D, Bersimbaev R, Izzotti A 2017. Resistance to cancer chemotherapeutic drugs is determined by pivotal microRNA regulators. Am J Cancer Res 7: 1350-1371.

Hanahan D, Weinberg RA. 2011. Hallmarks of cancer: the next generation. Cell 144: 646-674.

Hassan M, Watari H, Abu Almaaty A, Ohba Y, Sakuragi N. 2014 Apoptosis and molecular targeting therapy in cancer. Biomed Res Int 2014: 150845 .

Housman G, Byler S, Heerboth S, Lapinska K, Longacre M, Snyder N, Sarkar S. 2014. Drug resistance in cancer: An overview. Cancer (Basel) 6: 1769-1792.

Jain AJ, Nicholls A. 2008. Recommendations for evaluation methods. J Comput Aided Mol 22: 133-139.

Kufavera I, Abagyan R. 2012. Methods of protein structure comparison. Methods Mol Biol 857: 231-257

Kumar A, Gautam B, Dubey C, Tripathi PK. 2014. A review: Role of doxorubicin in treatment of cancer. Intl J Pharmaceut Sci Res 5: 4117 4128.

Kwak HH, Kim IR, Kim HJ, Park BS, Yu SB. 2016. $\alpha$-mangostin induces apoptosis and cell cycle arrest in oral squamous cell carcinoma cell. Evid Based Compl Alternat Med 2016: 5352412.

Lee HN, Jang HY, Kim HJ, Shin SA, Choo GS, Park SY, Kim SK, Jung JY. 2016. Antitumor and apoptosis-inducing effects of $\alpha$-Mangostin extracted from the pericarp of the mangosteen fruit (Garcinia mangostana L.) in YD-15 tongue mucoepidermoid carcinoma cells. Intl J Mol Med 37: 939-948.

Li F, Zhou X, Zhou H, Jia J, Zhai S, Yan B. 2016. Reducing both pgp overexpression and drug efflux with anti-cancer gold-paclitaxel nanoconjugates. PloS One 11: e0160042. DOI: 10.1371/journal.pone.0160042.

Liu B, Ezeogu L, Zellmer L, Yu B, Xu N, Liao DJ. 2015. Protecting the normal in order to better kill cancer. Cancer Med 4: 1394-1403.

Moongkarndi P, Kosem N, Kaslungka S, Luanratana O, Pongpan N, Neungton N. 2004. Antiproliferation, antioxidation and induction of apoptosis by Garcinia mangostana (mangosteen) on SKBR3 human breast cancer cell line. J Ethnopharmacol 90: 161-166.

Park SJ, Park BS, Yu SB, Kang HM, Kim HJ, Kim IR. 2018. Induction of apoptosis and inhibition of epithelial-mesenchymal transition by $\alpha$ mangostin in MG-63 cell lines. Evid-Based Compl Altern Med 2018: 3985082. DOI: 10.1155/2018/3985082.

Pistritto G, Trisciuoglio D, Ceci C, Garufi A, D’Orazi G. 2016. Apoptosis as anticancer mechanism: function and dysfunction of its modulators and targeted therapeutic strategies. Aging (Albany NY) 8: 603-619.

Ricci MS, Zong WX. 2006. Chemotherapeutic approaches for targeting cell death pathways. Oncologist 11: 342-357.

Rofida S, Sukardiman, Widyawaruyanti A, Arifianti L. 2017. Anti cancer activity of active substances from mangosteen pericarp (Garcinia mangostana L.) against T47 D Cell Lines. AHSR 2: 274-281

Setiawati A, Riswanto FOD, Yuliani SH, Istyastono EP. 2014. Anticancer activity of mangosteen pericarp dry extract against MCF-7 breast cancer cell line through estrogen receptor- $\alpha$. Indonesian J Pharm 25: 119-124.

Shah MA, Schwartz GK. 2001. Cell cycle-mediated drug resistance: An emerging concept in cancer therapy. Clin Cancer Res 7: 2168-2181.

Toffoli G, Corona G, Gigante M, Boiocchi M. 1996. Inhibition of Pgp activity and cell cycle-dependent chemosensitivity to doxorubicin in the multidrug-resistant LoVo human colon cancer cell line. European J Cancer 32: 1591-1597.

Ueda JY, Tezuka Y, Banskota AH, Tran QL, Tran QK, Harimaya Y, Saiki I, Kadota S. 2002. Antiproliferative activity of Vietnamese medicinal plants. Biol Pharm Bull 25: 753-760. 